\title{
La vigencia del Presupuesto ordinario en las Corporaciones locales
}

\author{
por \\ MIGUEL FIGUEIRA LOURO \\ Interventor de Fondos de Administración local. Abogado
}

SUMARIO: I. Preliminares.-II. Iniciación del Presupuesto.-III. Terminación. del Presupuesto.-TV. Presupuestos prorrogados.-V. Presupuestos bienales.

\section{PRELIMINARES}

El Presupuesto ordinario es norma fundamental en las Corporaciones locales; rige preceptivamente su vida económica y financiera. Las Corporaciones locales formarán para cada ejercicio económico un Presupuesto ordinario (artículo 675 de la Ley de Régimen local), con vigencia durante ese ejercicio coincidente con el año natural, o sea de 1 de enero a 31 de diciembre.

Ante esa obligada vigencia del Presupuesto ordinario se precisa estructurar un sistema que garantice, de un lado, que el Presupuesto comenzará a regir precisamente en 1 de enero; de otro, que su finalización en 31 de diciembre de cada año no interrumpirá las relaciones jurídicas que hayan quedado pendientes del ejercicio. Con independencia de ello se plantean situaciones especiales en orden a la vigencia del Presupuesto que pueden conceptuarse como excepciones al régimen general aludido.

El presente trabajo intenta estudiar esos limitados aspectos del Presupuesto ordinario. 


\section{INICLACION DEL PRESUPUESTO}

1. El Presupuesto ordinario nace a la vida, o debe nacer, en primero de cada año. La legislación local está orientada en este aspecto a asegurar el cumplimiento de esa norma cardinal, teniendo en cuenta que la confección del Presupuesto es compleja y dilatada, a lo que se une la necesidad de que esa gestación tenga lugar en época tal que quepa razonablemente prever los gastos y los ingresos a realizar en el futuro ejercicio.

$\mathrm{Y}$ así :

El Interventor tiene obligación de formar el Anteproyecto (artículo 680,1, de la Ley de Régimen local y 185 del Reglamento de Haciendas locales). El propio Reglamento preceptúa que esa obligación será cumplida «al término del mes de julio». Por su parte, el Presidente de la Corporación, asistido del Secretario y del Interventor, y tomando como base el Anteproyecto, formará el Proyecto de Presupuesto (artículo 680,1, de la Ley de Régimen local y 186 del Reglamento de Haciendas locales). Se le concede cierta holgura de tiempo: el Proyecto ha de ser elevado a la Corporación antes de la segunda decena del mes de septiembre (artículo 680,2, de la Ley de Régimen local).

La aprobación compete a la Corporación; en todo caso antes del día 10 de octubre (artículo 681 de la Ley de Régimen local).

Como trámite esencial del expediente figura la exposición al público por término de quince días (artículo 682 de la Ley de Régimen local). La Ley considera que durante el período 10 de octubre-30 de noviembre hay tiempo holgado para la exposición, ya que impone a la Corporación la obligación de remitir copia del expediente y del Presupuesto a la Delegación de Hacienda dentro de la última decena del mes de noviembre (artículos 685 y 686 de la Ley de Régimen local), háyanse o no formulado reclamaciones. Por fin, la Delegación de Hacienda debe resolver en el plazo de un mes (artículo 685,2, de la Ley de Régimen local), salvo ampliación del plazo por haberse solicitado de la Corporación informes, datos o documentos como requisito previo a la decisión.

El sistema es lógico. Si los Presupuestos ordinarios deben comenzar a regir en primero de enero de cada año, los sucesivos 
trámites de su confección han de tener previsto un plazo holgado y suficiente que permita en condiciones normales poner en ejecución el Presupuesto en la fecha que la Ley desea; y tan próximo al Ejercicio en que el Presupuesto haya de regir como sea posible, a fin de que éste sea racional y ajustado a la realidad.

2. Mas, ¿cómo lograr la efectividad de esas sucesivas funciones de los órganos del Ente local? Llegados a este punto justo es reconocer que el incumplimiento de los plazos que la Ley señala está por demás generalizado. Quizá sea debido en gran parte a la profunda crisis que en el orden económico y financiero están atravesando los Entes locales, a los que cada día se les hace más difícil nivelar sus Presupuestos y atender debidamente a las cargas que sobre ellos recaen; influye también el conjunto de transformaciones hacendísticas que se vienen operando desde diciembre. de 1962, e incluso que las Instrucciones de Presupuestos vienen desde hace algún tiempo promulgándose en época tardía. Así, las. reguladoras de la formación de Presupuestos para el Ejercicio de 1964, aprobadas por Orden de 12 de diciembre de 1963, fueron publicadas en el Boletín Oficial del Estado de 23 del mismo mes y año; y las correspondientes al Ejercicio de 1965, aprobadas por Orden de 26 de diciembre de 1964, se insertan en el Boletín Oficial del Estado de 7 de enero de 1965, fechas en que, según las previsiones de la Ley de Régimen local, ya todos los Presupuestos debieran estar en la Delegación de Hacienda, y no sólo eso, sino sancionados y en ejecución.

Bien es verdad que no es de rigor que las Instrucciones de Presupuestos hayan de promulgarse anualmente. En puridad, con Instrucciones o sin Instrucciones, los Presupuestos deben estar aprobados por las Corporaciones antes del 10 de octubre de cada año. Mas es indudable que tales Instrucciones, de gran valor, ya son una costumbre en la Administración local, de tal forma que cabe disculpar que por ellas se espera, y máxime en época de profundas transformaciones.

Lo cierto es que por unas u otras causas, el incumplimiento de plazos en la tramitación del Presupuesto se ha convertido en ordinario y normal.

3. Cuando ese incumplimiento es de tal alcance que el Pre-. 
supuesto no llegue a ser aprobado por la Delegación de Hacienda con tiempo suficiente para que comience a regir en primero de enero lleva consigo una consecuencia inmediata: la de haber de regir interinamente el del Ejercicio anterior, con absoluta exclusión de todo gasto voluntario (artículo 688 de la Ley de Régimen local). Solución de todo punto necesaria, porque no cabe prescindir del Presupuesto ordinario y en consecuencia no hay otro remedio que acudir al formado para el del Ejercicio anterior. Sin ello ni podrían contraerse ni efectuarse pagos o ingresos. Pero las limitaciones que se imponen, prohibición de todo gasto voluntario, son de importancia suma; si se piensa que es a través del gasto voluntario el cauce por donde en gran parte se desarrolla la actividad de gestión de las Corporaciones, se comprenderá la gravedad de la medida (artículo 706 de la Ley de Régimen local), similar a la que se produce con el déficit en el Presupuesto refundido (artículo 689 de la Ley de Régimen local).

El artículo 688 de la Ley de Régimen local establece una prórroga obligada del Presupuesto del Ejercicio anterior, limitada, transitoria y circunstancial. Es una solución de emergencia, limitada exclusivamente a los gastos de naturaleza obligatoria; limitada también en los ingresos, pues, aunque expresamente no se diga, algunas de las exacciones no podrán ponerse en ejecución: así sucederá con aquellas que supongan correlación a un gasto de tipo voluntario, como la prestación personal y las contribuciones especiales.

El precepto a que nos referimos como previsor de una situación anómala mantiene en todo su vigor la obligación corporativa de formar el Presupuesto y someterlo a la aprobación de la Delegación de Hacienda.

Pero la Ley de Régimen local ya no prevé cómo actuar frente a Corporación que persiste en su pasiva actitud. Tan sólo al tratar del Servicio Nacional de Inspección y Asesoramiento de las Corporaciones Locales encomienda a éste «inspeccionar su funcionamiento», «fiscalizar la gestión económica local», etc., pero realmente no se contempla fórmula directa que conduzca a la formación del Presupuesto. Incluso resulta insuficiente el artículo $12,1, h$ ) del Decreto de 26 de julio de 1956 sobre organización 
y funcionamiento del Servicio que encomienda a las Jefaturas provinciales «dar cuenta al Delegado de Hacienda de los Presupuestos pendientes de presentación y proponer a dicha autoridad el nombramiento de comisionados especiales para conseguir su remisión». Insuficiente porque por amplias que se conciban las facultades o poderes del comisionado, por cierto no regulados, no puede sustituir las atribuciones de los órganos corporativos y fun-. cionarios. De suerte que la labor del comisionado vendrá a quedar ređucida simplemente a una gestión de persuasión y asesoramiento.

Tan sólo cabría un procedimiento indirecto: La disolución del Ayuntamiento o Diputación por resultar su gestión gravemente: dañosa para los intereses de la Entidad. En situación tal como la expuesta estaría plenamente justificada la intervención del Es-tado (artículos 422, 423 y 424 de la Ley de Régimen local), sin perjuicio de las responsabilidades que procedan (artículo 412 de: la Ley de Régimen local).

4. Si algo llama particularmente la atención en la gestión del Presupuesto es la extremada complejidad y volumen del expediente. Tenemos entendido que se están realizando estudios se-rios en orden a la simplificación, a los que desde luego hay que dar la bienvenida; el ahorro de personal, tiempo, actividad y material, sin mengua de la claridad, supondrá una positiva mejora para las Corporaciones, sumidas en la actualidad en un impresionante mar de expedientes. Por otro lado, cuanto contribuya. a reforzar el conocimiento y compenetración con el Presupuesto, ya sea por los administrados, ya por las propias Corporaciones,. es finalidad plausible.

Hemos de apuntar algunas ideas que gustosamente sometemos a la crítica de los estudiosos:

A) La exposición al público de los Presupuestos de las Cor-. poraciones es requisito que nadie duda de calificar de esencial y necesario; lo exige la propia naturaleza de la Administración y de su actividad, inmersa en el Derecho. Debe darse ocasión a que tal actividad pueda ser conocida y eventualmente impugnada. Es a través de esa estrecha simbiosis entre Administra-. 
ción y administrados cómo las Corporaciones recibirán aliento vital, y máxime hoy en que cada día más se impone, y con renovado vigor, la participación del ciudadano en los negocios públicos.

En el sistema de la Ley de Régimen local esa exposición se inicia mediante la inserción de anuncio en el Boletín Oficial de la Provincia (artículo 682 de la Ley de Régimen local). La exposición es individual, de cada Presupuesto, independiente y dispar, varia en el tiempo. En tal procedimiento hay un algo y aun un mucho de ficción basada en una presunción de conocimiento del Boletín Oficial. Pero el periódico oficial no está al alcance de todo el mundo, y aun aquellos que a su disposición lo tienen precisan de meticuloșo cuidado para que el anuncio no les pase desapercibido.

Creemos que estos inconvenientes podrían soslayarse fácilmente: Pues si es preceptivo que los Presupuestos han de estar aprobados por las Corporaciones antes del día 10 de octubre de cada año, aprovéchese esta coyuntura para declarar la exposición automática de todos los Presupuestos ordinarios durante los quince días hábiles inmediatamente siguientes al 10 de octubre, sin necesidad de la inserción del anuncio en el Boletín Oficial de la Provincia. Medida sencilla con la que se conseguiría ahorro de actividad municipal, mayor ahorro de actividad en el Boletín Oficial de la Provincia y conocimiento cierto para todos los administrados y en la totalidad de las Corporaciones, de forma que la exposición quedaría más garantizada; sería una exposición libre por completo de ficciones o presunciones y no sometida al retraso que pueda derivar del volumen de trabajo en la Administración del Boletín Oficial de la Provincia.

En contra podría alegarse que no todas las Corporaciones tienen sus Presupuestos aprobados en 10 de octubre. Mas, aparte de que sí deben estarlo, de tal suerte que incluso se produciría un más perfecto control de la actividad municipal, para tales casos cabría arbitrar un procedimiento subsidiario, el cual encontramos en una doble dirección: publicación expresa en el Boletín Oficial y obligación de notificar individualmente al que ha- 
biéndose personado en el período de exposición para examinar el Presupuesto se encontrase con que éste pendía de aprobación.

B) Las reclamaciones en materia de Presupuestos no son resueltas por la Corporación (artículo 683 de la Ley de Régimen local). Se dirigen en todo caso al Delegado de Hacienda que decide sobre ellas previo informe del Presidente de la Corporación, pues aun cuando el artículo 686 de la Ley de Régimen local dispone que «las Corporaciones remitirán las reclamaciones al Delegado de Hacienda debidamente informadas», el artículo 190 del Reglamento de Haciendas locales concreta que el informe-compete en todo caso al Presidente.

$\mathrm{Y}$ ello resulta curioso, ya que es norma general que contra los actos y acuerdos de las Corporaciones locales cabe recurso de reposición (artículo 377 de la Ley de Régimen local), incluso en materia de multas, reclamaciones económico-administrativas y demás referentes a Haciendas locales, bien que potestativo en estos casos (artículo 380 de la Ley de Régimen local). No alcanzamos el fundamento para excluir el Presupuesto de ese régimen normal. La anomalía, si es tal, sube de punto si consideramos que la Corporación puede ni llegar a tener conocimiento de las reclamaciones formuladas contra los Presupuestos por ella aprobados, porque si la resolución compete al Delegado de Hacienda, el informe incumbe al Presidente, como hemos visto, previo dictamen del Interventor.

Nos parece que debe otorgarse a la Corporación atribuciones para resolver y decidir sobre las reclamaciones, sin perjuicio de la competencia ordinaria del Delegado de Hacienda, a quien en todo caso incumbiría conocer de las desestimadas. Por lo demás, por premuras de tiempo, el plazo para que la Corporación haya de resolver forzosamente habría de ser limitado, diez días por ejemplo, a partir de la finalización del período de exposición.

C) A lo largo de toda la tramitación del Presupuesto se observa la ausencia total de intervención de la Comisión municipal Permanente, que en cambio participa con carácter ordinario y normal durante la vigencia del mismo: «contratación de 
obras y servicios cuya duración no exceda de un año o que no exijan créditos superiores a los consignados en el Presupuesto anual del Ejercicio»; «desarrollo de la gestión económica conforme al Presupuesto aprobado», etc. (artículo 122 de la Ley de Régimen local).

Ahora bien, si se piensa que el Presupuesto es previsión de gastos e ingresos para un Ejercicio que regirá la vida de la Entidad durante un año, modo el ordinario de imprimir carácter y dirección determinada a la gestión municipal, parece anómalo que la Comisión municipal Permanente como tal carezca de ocasión para contribuir a la previsión de tales directrices, tanto más cuanto que está constituída por los Tenientes de Alcalde (artículo 75 de la Ley de Régimen local), miembros los más cualificados del Ayuntamiento y que tiene a su cargo ya los Distritos, ya los grupos generales de servicios (artículo 17 del Reglamento de Organización, Funcionamiento y Régimen jurídico). Los Tenientes de Alcalde, hay que presumirlo, son los que reúnen condiciones más idóneas para discutir, estudiar y trazar las orientaciones fundamentales en orden al Presupuesto. Si a ello se une que la Comisión municipal Permanente debe estar plenamente identificada con la norma presupuestaria y que el Ayuntamiento Pleno por su composición y número de miembros no es el más adecuado para la discusión y votación de todas y cada una de las partidas y conceptos del Presupuesto, se sugiere prever la directa participación de la Comisión Permanente en la confección del Proyecto. $\mathrm{Y}$ realmente, la experiencia demuestra que los Alcaldes asocian a los Tenientes de Alcalde a la formación del Proyecto, de tal suerte que una regulación legal de esta intervención vendría a consagrar una realidad que por la naturaleza misma de las cosas se impone con vigor.

En suma, según nuestra concepción, el Anteproyecto correspondería al Presidente, con la colaboración de Secretario e Interventor; el Proyecto a la Comisión municipal Permanente, y el Presupuesto al Pleno de la Corporación. En los Ayuntamientos carentes de Comisión Permanente, podría ser sustituída por Comisión similar a la que contempla el artículo 790 de la Ley de Régimen local. 
D) Estimamos interesante examinar la documentación que debe figurar en el expediente para juzgar la posibilidad de introducir alguna modificación, en especial respecto de Entidades de pequeña envergadura. Porque en efecto, del expediente de Presupuesto debe eliminarse todo aquello cuya utilidad no compense la inversión de trabajo.

a) Ni la Ley de Régimen local ni el Reglamento de Haciendas locales contienen normas específicas indicadoras del formato del Proyecto. Se deduce, no obstante, que es similar al propio Presupuesto, estructurado en Capítulos, Artículos y Conceptos, numerados éstos correlativamente en el Estado de Ingresos; y en Capítulos, Artículos, Conceptos y Partidas, numeradas correlativamente, en el Estado de Gastos (artículos 677 y 676 de la Ley de Régimen local).

Esta simplicidad inicial del Proyecto, tal como se deduce de dichos textos fundamentales, ha venido a complicarse no poco con las Instrucciones de Presupuestos. Así las Instrucciones para 1960, aprobadas por Orden de 31 de julio de 1959, y reiteradas en años sucesivos, exigen unir al Proyecto un Estado de Modificaciones, tanto en gastos como en ingresos, bastante complejo. Sólo aquel que ha de confeccionar el Estado de Modificaciones tiene clara conciencia de lo trabajoso que resulta; y todo aquel que por obligación o función ha de examinar o ejecutar el Presupuesto sabe cuán poco provecho reporta en la práctica. Realmente su utilidad se cifra en consistir en un estado comparativo entre un Proyecto de Presupuesto para Ejercicio venidero y el Presupuesto del Ejercicio corriente. Salta a la vista que siendo el Proyecto un documento preparatorio, la utilidad de la comparación es muy limitada, lo mismo para la Entidad, ya aprobado el Presupuesto, que para la Delegación de Hacienda al examinarlo. Pues en efecto, si a la Corporación le surge durante el Ejercicio la necesidad o conveniencia de hacer comparaciones, las hará entre Presupuesto y Presupuesto, no entre Presupuesto y Proyecto; y lo mismo a la Delegación de Hacienda. De forma que la utilidad del Estado de Modificaciones viene a ser en todo caso muy relativa.

b) Al Proyecto debe acompañarse la propuesta de las Bases 
de Ejecución (artículo 679 de la Ley de Régimen local). Tanto de la propuesta como de las propias Bases cabe prescindir en situaciones ordinarias, que es lo general. Bastaría a tal efecto promulgar unas Bases de ejecución tipo, facultando a las Corporaciones para adaptarlas a las peculiaridades de cada Entidad e incluso ampliarlas. Las ventajas serían patentes, pues además de conseguirse con ello una relativa uniformidad de criterios, de la inmensa mayoría de los Ayuntamientos desaparecería tal documento que en general no es sino una recopilación más o menos exhaustiva de preceptos legales.

c) A primera vista la certificación de gastos forzosos que ha de unirse al Proyecto (artículo 680, 2, a) de la Ley de Régimen local) parece un documento fundamental, básico, pues naturalmente si el Presupuesto tiene como finalidad principal la de satisfacer tales gastos, éstos deben constar fehacientemente y con carácter previo. La práctica, no obstante, ha puesto de relieve algo curioso. $\mathrm{Y}$ es que ni el Proyecto ni el Presupuesto se basan generalmente en la certificación de gastos forzosos. Sucede cabalmente al revés, que el Proyecto o el Presupuesto sirven de base ordinariamente para la expedición de la certificación, por donde se ve que la finalidad de ésta queda en parte truncada. Si alguien tiene la paciencia de examinar Presupuestos podrá observar que la certificación de gastos forzosos es un trasunto, un fiel reflejo del Presupuesto, hasta el extremo de que como respecto de gastos forzosos cada cual tiene sus propias interpretaciones, para obviar tal inconveniente se incluyen en la misma gastos típicamente voluntarios, incluso imprevistos. De esta forma la certificación de gastos forzosos ha venido a parar en un auténtico formalismo.

d) Conceptuamos fundamental la certificación de ingresos percibidos (artículo 680, 2, b) de la Ley de Régimen local). Pero se facilitaría en extremo la comparación si se refiriese no a los ingresos percibidos, sino a los liquidados y contraídos aunque no estuviesen recaudados. De ese modo se haria innecesaria la certificación de ingresos anulados. $Y$ ello es así porque lo verdaderamente interesante es adquirir la certidumbre de que las previsiones de ingresos en el Proyecto y en el Presupuesto tienen una base firme deducida de la gestión de ejercicios anteriores. 
No interesa, pues, la recaudación, ni tampoco las consignaciones anuladas: lo interesante es lo que se ha liquidado (artículo 677, c) de la Ley de Régimen local).

Por otro lado, bien se comprende que la certificación de ingresos referida a los seis primeros meses del año en que el Proyecto se confecciona carece de valor salvo para aquellas exacciones que se recaudan mensualmente. Para aquellas otras que se cobran por padrón, $y$ en especial con cuotas inferiores a quinientas pesetas, esa parte de la certificación carece de significación. En consecuencia, no es para la formación del Proyecto donde resulta necesaria la certificación referida a la recaudación de los seis primeros meses del Ejercicio corriente, ya que ésta está a la vista en otros documentos municipales a disposición de los que confeccionan el Proyecto, sino en otro caso, y referida a los nueve meses primeros del año, siempre más completa, para unir al Presupuesto en el momento de ser aprobado por la Corporación, como una justificación de las previsiones de ingresos ante la Corporación y ante la Delegación de Hacienda.

e) Por lo que afecta a la certificación de ingresos anulados, ya hemos apuntado nuestra opinión. Por lo que atañe a la de créditos anulados y suplementos y habilitaciones de crédito no la estimamos esencial. Porque ya no es sólo que la determinación de los gastos incumbe a las Corporaciones, respetando los forzosos, sino por el hecho de que esta certificación se refiere a un Ejercicio cerrado, sin repercusión directa dos años más tarde (artículo 680,2, c) de la Ley de Régimen local).

f) Juzgamos de importancia suma el documento referente a las bases de cálculo de los ingresos que se arbitren por vez primera, que debe ampliarse también a la situación a que alude el apartado c) del artículo 677 de la Ley de Régimen local, o sea, a los supuestos en que se consignen cantidades superiores al rendimiento obtenido en el último Ejercicio liquidado (artículo 680, 2, d) de la Ley de Régimen local).

g) Es inoperante el informe sobre la inexistencia de déficit inicial. La inexistencia del déficit resulta de la simple comparación entre los totales del Estado de Gastos y el de Ingresos. Cosa distinta es que exista déficit inicial encubierto por elevación fic- 
ticia de ingresos o falta de consignación de gastos necesarios; pero aparte de que tal circunstancia no ha de ser puesta de manifiesto por el Interventor, generalmente, ello se deducirá del detenido estudio del Estado de Ingresos en relación con lo liquidado en ejercicios anteriores y bases de cálculo. Es, pues, otra certificación rigurosamente formalista (artículo 187, a) del Reglamento de Haciendas locales).

h) La certificación de gastos de personal (artículo 187, b) y c) del Reglamento de Haciendas locales) podría contener: Relación detallada de todos los gastos de personal correspondientes a la plantilla de la Corporación, con separación, a efectos del artículo 331 de la Ley de Régimen local, de los de personal técnico y administrativo, del resto de los funcionarios y el total de ambos, y referida a las retribuciones que tengan carácter general y legal. Relación detallada de las retribuciones especiales del personal de plantilla que con arreglo a la Ley 108/1963 exijan autorización del Ministerio de la Gobernación, acreditando por diligencia el otorgamiento de la misma, y con la debida separación entre personal técnico y administrativo y resto de personal. Relación detallada de los gastos dé personal al margen de la plantilla. Diligencia acreditativa que todos los gastos relacionados figuran en el Proyecto de Presupuesto y de los porcentajes que respecto al mismo representan conforme a los artículos $90 \mathrm{del}$ Reglamento de Funcionarios y 331 de la Ley de Régimen local, acreditando la pertinente autorización ministerial si tales porcentajes fuesen rebasados. Diligencia acreditativa de la población del Municipio.

\section{TERMINACION DEL PRESUPUESTO}

A) El Presupuesto ordinario de las Corporaciones locales, ley económica temporal, que ciñe su vigencia al ejercicio económico, se extingue con éste en 31 de diciembre. Con el cierre del Ejercicio se inician las operaciones de liquidación.

El artículo 693 de la Ley de Régimen local dispone que al fin de cada Ejercicio quedarán anulados los créditos abiertos, no invertidos ni comprometidos durante la vigencia del Presupuesto. 
En adelante ya no pueden realizarse con cargo a él contraído alguno. El Presupuesto ha fenecido.

Pero naturalmente durante su vigencia y a su amparo han surgido a la vida una serie de relaciones jurídicas, todavía no consumadas y que han de pervivir al propio Presupuesto; de tal forma que las operaciones de liquidación al mismo tiempo que resumir la gestión anual se encaminan a depurar, relacionar y concretar esas relaciones pendientes que han de llegar a su culminación en nuevo Ejercicio económico. En la vida de los Entes locales no se conciben los Presupuestos como absolutamente independientes, sino armónicamente enlazados.

Esas operaciones de depuración se concretan en un Inventario de deudas, Resultas de Gastos, relación de las obligaciones reconocidas y pendientes de pago el último día del Ejercicio, y en un Inventario de créditos, Resultas de Ingresos, relación de los pendientes de cobro y existencia en Caja en el mismo día. El resultado final se deduce de una simple comparación: si los créditos pendientes de cobro y la existencia en Caja superan a las obligaciones pendientes de pago la liquidación arrojará superávit; será deficitaria si la situación es inversa.

B) Surge así una herencia, positiva o negativa, que tiene un natural y forzoso heredero: el nuevo Presupuesto que va a resultar poderosamente influído por la carga o la riqueza que le viene encima, hasta el punto que tras asumir las relaciones procedentes del anterior transforma su personalidad y su nombre. Ya no es el Presupuesto preventivo, es el Presupuesto refundido.

Esa influencia actúa según el signo de la liquidación anterior. El superávit es manantial que refuerza el nuevo Presupuesto y que puede ser empleado del más vario modo, incluso para nutrir un Presupuesto extraordinario (artículo 695 de la Ley de Régimen local). Si la herencia es negativa el nuevo Presupuesto tiene que asumir la carga, casi siempre con grave extorsión. Porque si el déficit no es compensado por superávit anterior no empleado o por un superávit inicial del Presupuesto preventivo, transforma automáticamente en deficitario al Presupuesto refundido, en el que los gastos superan a los ingresos previstos. 
Situación anormal y extremadamente peligrosa, enfermedad grave en la vida de las Corporaciones que decididamente exige se adopten medidas urgentes encaminadas a su eliminación. El descuido, la negligencia, la irresponsabilidad, conduce al déficit crónico en el que padecen todas las facetas de la Administración y que justifica la injerencia del Estado en el régimen de la Corporación para someterla a tutela como positivamente incapaz (artículo 425 de la Ley de Régimen local).

Detectado el déficit se impone extirparlo como un tumor y a plazo corto. $Y$ no hay más cirugía, no hay otro remedio eficaz que ahorrar para llegar a una economía de las consignaciones en gastos, complementado con una gestión decidida de los ingresos a fin de rebasar las previsiones presupuestarias, elementos ambos de signo positivo a la hora de liquidar.

No es, pues, solamente una sanción a la Corporación la obligación que se le impone en estos casos de prescindir de los gastos autorizados en Presupuesto que tengan el carácter de voluntarios (artículo 689 de la Ley de Régimen local); es, sobre todo, la expresión legal de que así, sólo así, podrá eliminarse el déficit. Si tal medida aún fuese insuficiente deberá completarse con las previsiones oportunas en el siguiente Presupuesto preventivo (artículo 689 de la Ley de Régimen local), pues conforme al artículo 676 una de las finalidades del Presupuesto ordinario es la de enjugar el déficit de Ejercicios anteriores. $Y$ así, está terminantemente prohibido el enjugarlo por medio de un Presupuesto extraordinario (artículo 694 de la Ley de Régimen local).

C) Es absolutamente cierto que la vigencia del Presupuesto termina con el Ejercicio económico. Esta sincronía es principio fundamental y básico, hasta el punto que se da incluso en situaciones excepcionales en las que aparentemente quiebra el principio. Hemos de verlo al tratar de Presupuestos prorrogados y bienales.

Ahora interesa hacer notar que en 31 de diciembre el Presupuesto ha fenecido irremediable y definitivamente. Porque aun cuando el artículo 688 de la Ley de Régimen local sienta como medida de emergencia que para el supuesto de que en primero 
de enero siguiente no esté aprobado el nuevo Presupuesto habrá de regir interinamente el Presupuesto anterior con absoluta exclusión de todo gasto voluntario, ello, creemos, no es así con exactitud. Lo que sucede simplemente es que ha nacido un nuevo Presupuesto que, aún interino, tiene entidad distinta del anterior, personalidad que si por algún otro Presupuesto ha de estar influenciada es por el nuevo, del que viene a ser un desarrollo anticipado y limitado, no por el antiguo. Hasta el punto que todos los contraídos, todos los ingresos, todos los pagos, han de ser imputados el nuevo Presupuesto, y con él liquidados, de tal suerte que la liquidación del Presupuesto del Ejercicio anterior ni se interrumpe ni se suspende. $Y$ aun en el caso anómalo que el nuevo Presupuesto no llegue a aprobarse en el decurso del Ejercicio, la Corporación viene obligada a proseguir su actividad, aplicando el superávit del pasado Ejercicio, bien que con la limitación que ha de ser para hacer frente a atenciones necesarias y urgentes, limitación que ahora alcanza mayor relieve por el efecto conjunto de los artículos 691 y 688 de la Ley de Régimen local; e igualmente puede hacer transferencias de créditos voluntarios del Presupuesto interino para reforzar las previsiones de gastos obligatorios, o habilitarlos caso de inexistencia de crédito.

En suma, el Presupuesto interino en el artículo 688 regulado es, o bien un Presupuesto preparatorio que ha de quedar inmerso en el nuevo o, si éste no llega a nacer, un Presupuesto auténtico, surgido por imperio de la ley y sujeto a limitaciones, y que como tal ha de dar lugar a su propia liquidación. En todo caso, sin más relación con el anterior en cuanto a su entidad que la materialidad de su igual importe; es, si se quiere, igual, pero no el mismo.

\section{PRESUPUESTOS PRORROGADOS}

A) Dispone el artículo 690 de la Ley de Régimen local que el Presupuesto ordinario podrá ser prorrogado por un solo año. El artículo 194 del Reglamento de Haciendas locales desarrolla, aunque fragmentariamente, este precepto legal.

Dado que según nuestra opinión lo que individualiza esencialmente a un Presupuesto es su aplicación a determinado Ejercicio, 
sostenemos que el Presupuesto prorrogado es un Presupuesto distinto. No es, pues, que el Presupuesto anterior perviva durante nuevo Ejercicio; ese Presupuesto ha cumplido su misión y se ha extinguido y se ha liquidado; de él han quedado unas secuelas, las Resultas, y un resultado, el déficit o el superávit, que han de ser incorporados a nuevo Presupuesto. Evidentemente, a la uniformidad de Presupuestos sucesivos que se consigue con la prórroga podría llegarse por el procedimiento normal de confección, en cuyo caso, aun siendo iguales los Presupuestos, nadie podría argumentar que se trataba del mismo.

La prórroga tiene un efecto inmediato: el ahorro de actividad por parte de los organismos encargados de la confección del Presupuesto. Sin embargo, es menester advertir que el mecanismo de la prórroga es delicado. Tan sólo cuando se den las circunstancias idóneas cabe acudir a ella; en otro caso, la prórroga es contraproducente, expuesta a contratiempos y a gran confusión. El determinar cuándo la prórroga es conveniente y aconsejable es cuestión técnica, delicada, que exige ponderación y estudio. $\mathrm{Y}$ sucede que las prórrogas se acuerdan en épocas difíciles, cuando menos indicadas están, épocas de transformaciones profundas y de oscilaciones grandes en las Haciendas, muchas veces para eludir estudios arduos que se dilatan para tiempo posterior.

Son requisitos de la prórroga:

a) El informe del Interventor. Indudablemente este informe es de todo punto necesario. Sólo el estudio del Interventor, profundo y meticuloso, justificará la conveniencia o necesidad de la prórroga, y si para ella concurren las condiciones idóneas.

El Presupuesto prorrogado es por naturaleza una repetición del anterior. De ahí que no procedería la prórroga si en el Estado de Ingresos han de mantenerse unas previsiones que la experiencia ha patentizado que son exageradas, o que por supresión de la exacción o modificación de la base imponible surja la evidencia de que tales previsiones no llegarán a alcanzarse. La prórroga en supuestos tales vendría a encubrir un déficit inicial que está prohibido (artículo 678 de la Ley de Régimen local) y a burlar el apartado c) del artículo 677. Cabría, en cambio, la prórroga aun a sabiendas de que los ingresos previstos habrían de resultar re- 
basados, pues esa es norma de buena administración que a la postre ha de traducirse en superávit. Lo no indicado es dar cabida en el Presupuesto por el sistema de prórroga a ese exceso de ingresos que se calculan.

La rigurosidad en el estudio del Estado de Ingresos a efectos de la prórroga cede bastante en lo que a gastos atañe. Pues, en efecto, el mecanismo de la habilitación o suplemento, ya durante el Ejercicio, puede paliar dificultades que sobrevengan. El propio Reglamento de Haciendas locales contiene el germen de esta doctrina, pues al disponer que la prórroga no puede afectar a los servicios que definitivamente deban terminar dentro del Ejercicio para el que el Presupuesto fué aprobado, está pregonando la posibilidad de que en el Presupuesto prorrogado existan consignaciones en gastos puramente nominales, sin contenido real, y de las que cabe hacer uso mediante transferencia.

Lo esencial en el terreno de los gastos es que todos los de naturaleza forzosa y obligatoria tengan su pertinente previsión; en otro caso tampoco sería procedente la prórroga, pues ésta no puede ser de mejor condición que el propio Presupuesto que ha de contener todos los gastos forzosos y cuya aprobación por la Delegación de Hacienda ha de ser denegada por ausencia de consignación de gastos obligatorios (artículo 191, 1 a) del Reglamento de Haciendas locales).

$\mathrm{Y}$ precisamente ese menor rigor en el Estado de Gastos que hemos visto tiene su apoyo en el Reglamento de Haciendas locales, se refleja en el Estado de Ingresos en alguna ocasión. Y así, cabría informar favorablemente la prórroga de un Presupuesto en el que figure en ingresos una subvención concedida para una obra o servicio determinados, con contrapartida en gastos. Realmente, nada impediría la supresión de ambos, aun con la obligada disminución del importe total del Presupuesto.

En suma, son presupuestos esenciales previos a la prórroga: Correlación del Estado de Ingresos con la realidad de la vida hacendística del Ente local, sin que en ningún caso puedan variarse las previsiones, ni en aumento ni en disminución, pues ello entrañaría la necesidad de formar Presupuesto por procedimiento normal. Tan sólo cabría la supresión de aquellas previsiones de in- 
gresos finalistas con correlativa consignación en gastos voluntarios que también desaparezcan. $Y$ previsión de todos los gastos de naturaleza forzosa $u$ obligatoria. Como caso excepcional hay que admitir que en el momento de acordarse la prórroga puede la Corporación destinar las consignaciones de los servicios definitivamente terminados a otros distintos, pues si ello es factible mediante transferencia de créditos, debe serlo también por extensión en el expediente de prórroga.

b) La decisión de la prórroga incumbe a la Corporación. El acuerdo deberá ser adoptado por la mayoría exigida para la aprobación del Presupuesto (artículos 194 del Reglamento de Haciendas locales y 681 de la Ley de Régimen local). En cuanto al tiempo, se amplía el plazo hasta el 10 de noviembre (idem ídem).

c) El Presupuesto prorrogado está sujeto a exposición. Las reclamaciones, sin embargo, se ciñen a situaciones creadas con posterioridad a la aprobación del primitivo Presupuesto. La prórroga se entenderá definitivamente aprobada si no se formularen reclamaciones, remitiéndose copia del expediente al Delegado de Hacienda para su conocimiento. Las reclamaciones interpuestas se tramitan y resuelven en la misma forma que se establece para los Presupuestos ordinarios (artículo 194 del Reglamento de Haciendas locales): $\mathrm{Y}$ entramos con ello en el aspecto más delicado de la prórroga, insuficientemente regulada, según creemos.

B) De no producirse reclamaciones la prórroga quedará definitivamente aprobada. El viraje respecto del sistema previsto para el Presupuesto es grande. Al Delegado de Hacienda, por lo que a la prórroga concierne, se le atribuye una función pasiva (artículo 194 del Reglamento de Haciendas locales).

Esa regulación es peligrosa, ya que se veda el examen y resolución que como competencia normal incumbe al Delegado de $\mathrm{Ha}$ cienda. Peligrosa porque en el expediente de prórroga pueden darse infracciones en su tramitación, inexistencia de condiciones idóneas que le sirvan de fundamento e incluso ausencia de consignación de gastos obligatorios; pero la Delegación de Hacienda se encuentra inerme ante una situación de la que tiene conocimiento y contra la que en puridad nada puede hacer; ni siquiera 
se arbitra recurso alguno de impugnación. En la práctica cabe se presenten problemas engorrosos, incluso de colisión de competencias, que se evitarían con la simple declaración legal de que la prórroga debe ser sancionada en todo caso por la Delegación de Hacienda, sin perjuicio del recurso económico-administrativo.

Pero los problemas que las reclamaciones plantean tampoco deben ser menospreciados. Las reclamaciones contra la prórroga acordada, aun cuando obedezcan a situaciones creadas con posterioridad a la aprobación del primitivo Presupuesto (artículo 194,4, del Reglamento de Haciendas locales), tienen un contenido similar a las reclamaciones contra el Presupuesto, o sea, por no haberse ajustado en su elaboración y aprobación a los trámites legales, por omitir el crédito necesario para el cumplimiento de obligaciones exigibles a la Entidad local, o consignarse para atenciones no preceptivas; y por manifiesta insuficiencia de los ingresos (artículo 684 de la Ley de Régimen local).

$\mathrm{Y}$ la estimación de algunas de ellas lleva consigo una consecuencia trascendental: la necesidad de alterar los créditos presupuestarios o las previsiones de ingresos, con repercusión obligada en el importe total del Presupuesto. De lo que en buena lógica se sigue que la estimación de las reclamaciones es incompatible con la prórroga. $\mathrm{Y}$ de ahí a devolver el expediente a la Corporación para que proceda a la formación del Presupuesto por procedimiento normal y debiendo tener en cuenta las reclamaciones estimadas, tan sólo media un paso. Nuestro criterio es que sí debe darse.

Véase, pues, como la regulación de la prórroga en lo tocante a atribuciones del Delegado de Hacienda ofrece puntos oscuros, susceptibles de controversia, y que con frecuencia llevarán a resoluciones dispares.

\section{PRESUPUESTOS BIENALES}

En el número 3 del artículo 675 de la Ley de Régimen local se dedican unas breves líneas a este punto. «El Ejercicio económico coincidirá normalmente con el año natural; pero las Corporaciones podrán acordar que los Presupuestos ordinarios se for- 
men para regir durante dos períodos anuales consecutivos, contados desde el 1 de enero al 31 de diciembre, que se cerrarán y liquidarán separadamente».

Parece que su redacción inicial está orientada a regular una excepción al principio general de que a cada Ejercicio económico corresponde un Presupuesto. Así cabe deducirlo de la contraposición entre las palabras «normalmente» $\mathrm{y}$ «pero». $\mathrm{Y}$, sin embargo, la frase final implica una importante restricción, tan importante que abre el campo a la polémica, pues aun cuando el precepto refiere el cierre y liquidación a cada Ejercicio, no al Presupuesto, no parece que esto pueda ser así si al mismo tiempo no se cierra y liquida un Presupuesto.

Podemos, pues, plantearnos la siguiente cuestión: ¿En los llamados Presupuestos bienales se trata de un Presupuesto único que ha de regir durante dos períodos anuales consecutivos, o bien se trata de dos verdaderos Presupuestos independientes, referido cada uno a distinto Ejercicio, que figuran en un mismo expediente y que son aprobados al mismo tiempo?

Nosotros nos inclinamos por la dualidad de Presupuestos. Concebimos el Presupuesto bienal como formado por dos Presupuestos, independizados, cada uno de los cuales ha de regir en período anual distinto y que ha de ser objeto de su propia liquidación. Así entendido, los dos Presupuestos pueden ser desiguales, lo mismo en gastos que en ingresos, ya en su cuantía, ya en la distribución de las consignaciones. Independientes, hasta el punto que durante el primer Ejercicio no procede hacer uso de los créditos correspondientes al segundo, ni efectuarse transferencias de créditos, sino dentro de cada uno de ellos. Terminado el primer Ejercicio comenzará a regir el segundo Presupuesto, al cual han de incorporarse los resultados de la liquidación del anterior. De esta forma, la particularidad única que el nuevo sistema representa sobre el normal es que la previsión de gastos e ingresos se formula a más largo plazo, de lo que se deduce que ello sólo estará indicado en épocas de normalidad, sin transformaciones, cuando la Corporación haya decantado en un «estatus» que no implique vaivenes grandes entre Ejercicio y Ejercicio. Porque la adecuación de gastos e ingresos a la realidad es tanto más dificultosa cuanto 
más separado esté el momento de la previsión del momento de la ejecución.

Pero esta tesis que sostenemos encuentra su más firme apoyo en argumentos de tipo negativo, precisamente por la imposibilidad de que sea de otra manera, o al menos dificultad grande.

Si se admite que el Presupuesto bienal es único con la especialidad de que su período de vigencia es más dilatado es evidente que las previsiones de gastos e ingresos serán desde luego de cuantía superior a las que procederían en un Presupuesto anual, y sin división alguna interna que separe lo a gestionar en cada uno de los dos períodos. En cuanto se establezca esa separación ya el concepto de Presupuesto bienal único se ha esfumado y volvemos a la tesis de Presupuestos distintos.

Pues bien, una primera observación muestra que el Presupuesto así estructurado e ideado es en extremo peligroso. No hay problema para aquellas atenciones que se reiteran periódicamente, como los gastos de personal; pero para muchas otras hay grave riesgo de que los créditos presupuestarios lleguen a agotarse o aminorarse notablemente durante el primer Ejercicio, de tal forma que la parte de Presupuesto a gestionar en el segundo vendría a quedar reducido a un esqueleto de Presupuesto, a un Presupuesto descarnado. Este peligro que apuntamos no es disquisición teórica, más o menos posible o probable; es tan real e inmediato que nos atrevemos a afirmar que será en extremo difícil que la liquidación del Presupuesto bienal único no arroje déficit.

Que ello es así, o puede serlo, cabe deducirlo de la propia naturaleza de las Corporaciones locales y de su composición. A las Corporaciones les importa menos las posibilidades económicas del Ente local que la satisfacción de las necesidades y servicios, de tal suerte que ante una atención que a sus ojos aparece como necesaria o conveniente buscan decididamente su satisfacción, relegando la posibilidad económica a un segundo plano y desde luego a resolver por los técnicos. De esto deben saber bastante los Interventores de Fondos que han de luchar diariamente para limitar las plausibles iniciativas de las Corporaciones, pero que muchas veces son irrealizables por falta de base económica; y eso en supuestos normales en que la inexistencia de crédito presu- 
puestario supone un serio valladar. Piénsese en lo que puede ocurrir si el crédito es holgado. Para el segundo Ejercicio en muchos casos tan sólo quedarán indicios de él.

Pero la improcedencia del Presupuesto bienal único, mejor dicho, la imposibilidad, dedúcese de que el número 3 del artículo 675 de la Ley de Régimen local dispone el cierre y liquidación separada de ambos Ejercicios. $Y$ si bien el cierre de un Ejercicio puede efectuarse sin que por ello haya de cerrarse el Presupuesto, no sucede lo mismo con la liquidación. A nuestro entender la liquidación de un Ejercicio implica liquidación de un Presupuesto, al menos según el concepto que de la liquidación tenemos en Administración local.

La liquidación destinada a precisar por el cómputo de los elementos positivos y negativos el superávit o déficit final debe contener como elementos positivos:

a) El superávit del Presupuesto definitivo.

b) El total exceso del importe líquido de los derechos reconocidos y liquidados sobre los recursos presupuestos definitivos.

c) La suma de las economías en gastos.

$Y$ como elementos negativos:

a) El déficit en su caso del Presupuesto definitivo.

b) El total exceso de los recursos presupuestos definitivos sobre el importe líquido de los derechos reconocidos y liquidados (Regla 76 de la Instrucción de Contabilidad de las Corporaciones locales).

Pues bien, no cabe pensar en practicar todas esas operaciones si el Presupuesto es único. Porque en tal supuesto, al final del primer Ejercicio no se han producido todavía excesos ni defectos en ingresos, ni tampoco economías en gastos, ni por ende es posible deducir un resultado final.

Esta imposibilidad, más que ninguna otra razón, nos mueve a sostener lo que anteriormente exponíamos: El Presupuesto bienal está constituído por dos Presupuestos independientes, que incluso pueden ser desiguales, y con vigencia consecutiva en dos Ejercicios económicos también consecutivos, que figurando en un mismo expediente se aprueban al mismo tiempo y han de ser liquidados separadamente. 